\title{
CORRECTION
}

\section{Correction: Degradation of small leucine-rich repeat proteoglycans by matrix metalloprotease 13 - identification of a new biglycan cleavage site}

Jordi Monfort',2, Ginette Tardif', Pascal Reboul', François Mineau', Peter Roughley ${ }^{3}$, Jean-Pierre Pelletier' and Johanne Martel-Pelletier*1

See related research by Monfort et al., http://arthritis-research.com/content/8/1/R26

\section{Correction}

After publication of our recent article [1], we noticed that the affiliation details provided for Dr Jordi Monfort were incomplete. This work was performed as part of the Doctorate in Medicine at the Universitat Autònoma de Barcelona. The author affiliations are now correct, as above.

\section{Author details}

'Osteoarthritis Research Unit, University of Montreal Hospital Centre, NotreDame Hospital, 1560 Sherbrooke Street East, Montreal, Quebec H2L 4M1, Canada. 'Department of Rheumatology, Universitat Autonoma de Barcelona, Hospital del Mar, Passeig Marítim de la Barceloneta, 25, 08005 Barcelona, Spain. ${ }^{3}$ Genetics Unit, Shriner's Hospital for Children, 1529 Cedar Avenue, Montreal, Quebec H3G 1A6, Canada.

\section{Published: 5 March 2013}

\section{References}

1. Monfort J, Tardif G, Reboul P, Mineau F, Roughley P, Pelletier JP, Martel-Pelletier $J$ : Degradation of small leucine-rich repeat proteoglycans by matrix metalloprotease-13: identification of a new biglycan cleavage site. Arthritis Res Ther 2012, 8:R26.

doi:10.1186/ar4183

Cite this article as: Monfort J, et al.: Correction: Degradation of small leucine-rich repeat proteoglycans by matrix metalloprotease 13 identification of a new biglycan cleavage site. Arthritis Research \& Therapy 2013, 15:401.
*Correspondence: jm@martelpelletier.ca

'Osteoarthritis Research Unit, University of Montreal Hospital Centre, Notre-Dame Hospital, 1560 Sherbrooke Street East, Montreal, Quebec H2L 4M1, Canada

Full list of author information is available at the end of the article 